OPEN ACCESS

Edited by:

Christoph Hölscher,

Research Center Borstel

(LG), Germany

Reviewed by:

Steven M. Holland,

National Institutes of Health (NIH),

United States

Yong-Soo Kwon,

Chonnam National University Medical

School, South Korea

*Correspondence:

Champa N. Ratnatunga

champa.ratnatunga@my.jcu.edu.au

John J. Miles

john.miles@jcu.edu.au

Specialty section:

This article was submitted to

Microbial Immunology,

a section of the journal

Frontiers in Immunology

Received: 25 October 2019

Accepted: 06 February 2020

Published: 03 March 2020

Citation:

Ratnatunga CN, Lutzky VP, Kupz A, Doolan DL, Reid DW, Field M, Bell SC, Thomson RM and Miles JJ (2020) The

Rise of Non-Tuberculosis

Mycobacterial Lung Disease.

Front. Immunol. 11:303.

doi: 10.3389/fimmu.2020.00303

\section{The Rise of Non-Tuberculosis Mycobacterial Lung Disease}

\author{
Champa N. Ratnatunga ${ }^{1,2,3,4 *}$, Viviana P. Lutzky ${ }^{4}$, Andreas Kupz ${ }^{1,2}$, Denise L. Doolan ${ }^{1,2}$, \\ David W. Reid ${ }^{4}$, Matthew Field ${ }^{1,5}$, Scott C. Bell ${ }^{4}$, Rachel M. Thomson ${ }^{6}$ and \\ John J. Miles ${ }^{1,2,5 *}$ \\ ${ }^{1}$ The Australian Institute of Tropical Health and Medicine, James Cook University, Cairns, QLD, Australia, ${ }^{2}$ Centre for \\ Molecular Therapeutics, James Cook University, Cairns, QLD, Australia, ${ }^{3}$ Faculty of Medicine, University of Queensland, \\ Brisbane, QLD, Australia, ${ }^{4}$ Immunology Department, QIMR Berghofer Medical Research Institute, Brisbane, QLD, Australia, \\ ${ }^{5}$ Centre for Tropical Bioinformatics and Molecular Biology, James Cook University, Cairns, QLD, Australia, ${ }^{6}$ Immunology \\ Department, Gallipoli Medical Research Institute, Brisbane, QLD, Australia
}

The incidence and number of deaths from non-tuberculous mycobacterial (NTM) disease have been steadily increasing globally. These lesser known "cousins" of Mycobacterium tuberculosis (TB) were once thought to be harmless environmental saprophytics and only dangerous to individuals with defective lung structure or the immunosuppressed. However, NTM are now commonly infecting seemingly immune competent children and adults at increasing rates through pulmonary infection. This is of concern as the pathology of NTM is difficult to treat. Indeed, NTM have become extremely antibiotic resistant, and now have been found to be internationally dispersed through person-to-person contact. The reasons behind this NTM increase are only beginning to be elucidated. Solutions to the problem are needed given NTM disease is more common in the tropics. Importantly, $40 \%$ of the world's population live in the tropics and due to climate change, the Tropics are expanding which will increase NTM infection regions. This review catalogs the global and economic disease burden, at risk populations, treatment options, host-bacterial interaction, immune dynamics, recent developments and research priorities for NTM disease.

Keywords: Non-tuberculous mycobacteria, pulmonary infection, mycobacteria, immunology, mycobacteria pathology

\section{INTRODUCTION}

Non-tuberculous mycobacteria (NTM) are ubiquitous, free living, environmental saprophytic organisms known to occupy water systems, soil, and vegetation. Belonging to the genus Mycobacterium (which include Mycobacterium tuberculosis (TB) and Mycobacterium leprae), there are over 170 identified NTM species with new species discoveries increasing yearly (1). NTM are microaerobic organisms which grow in 6-12\% oxygen and have lipid-rich cell walls and metabolic characteristics that result in a slow doubling time of 20-24h (1). These organisms can withstand a wide range of environmental temperatures, do not readily grow in standard bacterial culture media and are antibiotic and disinfectant resistant. Given these characteristics, NTM are found worldwide and cause infections that are easily missed, difficult to diagnose, and difficult to treat.

First described in the late nineteenth century (soon after Robert Koch's seminal description of M. tuberculosis as the causative agent of tuberculosis in 1882), decades passed before human NTM infection was identified (2). Since then over 90 species have been identified 
from human samples with several more remaining either unclassified or unidentified (3). NTM can be split into "slow" or "rapid" growers. An easy way to narrow down the species in the diagnostic setting. Species classification based on $16 \mathrm{~S}$ rRNA sequencing has revealed a great deal of complexity within the genus. Human infection is mostly caused by the slow growing Mycobacterium avium complex (MAC) which now includes MAC subspecies silvaticum, subspecies hominissuis, and subspecies paratuberculosis, Mycobacterium intracellulare, Mycobacterium arosiense, Mycobacterium chimera, Mycobacterium columbiense, Mycobacterium marseillense, Mycobacterium timonense, Mycobacterium bouchedurhonense, and Mycobacterium ituriense (1). Other common NTM isolated from human samples include Mycobacterium xenopi, Mycobacterium fortuitum complex, Mycobacterium kansasii, and the rapidly growing Mycobacterium abscessus group (MABS) which were recently grouped as a separate clade named Mycobacteriodes abscessus based on phylogenetic characteristics (4). The MABS group includes subspecies abscessus sensu stricto, subspecies massiliense and subspecies bolletii $(3,5)$. Collectively, these species comprise $80 \%$ of global clinical specimens (3).

The natural habitats for NTM range from natural brackish and marshy waters to municipal water distribution systems and household plumbing including shower heads (6). NTM are also found in potting soil and other peat rich soils. This overlap of bacterial habitat with human habitation provides an ideal opportunity for human infection. The lipid-rich hydrophobic cell walls of these organisms are ideal for biofilm formation which allows long-term persistence of bacterial colonies that are effectively resistant to disinfectants and generate aerosols, particularly from shower heads $(7,8)$. Organism density in shower aerosols is significantly higher than in the main water stream and is thought to be the most likely source for pulmonary infection $(1,9)$. Household based studies have shown a genotype match between environmental and clinical isolates (8) while a recent large scale study with multicentre sampling performed in both Europe and the US showed a high degree of overlap between geographical areas where NTM lung disease is common and a high density of potentially pathogenic organisms in shower and water source samples (10). Disturbingly, NTM have also been identified in hospital ice machines, water-cooling systems and haemodialysis unit water supplies. Exposure to these organisms is therefore likely to occur at home to healthcare centers $(1,2)$. Alarmingly, recent data has confirmed person-toperson transmission of highly virulent, clonal MABS across the globe (11).

\section{THE PATHOLOGY OF PULMONARY NTM INFECTION}

NTM disease presents a wide variety of clinical syndromes, from lymphadenopathy (commonly cervical lymph nodes) to aseptic meningitis. Infection of the lung is the most common clinical manifestation. Termed pulmonary NTM disease (PNTM), this manifestation has an evolving and complex pathology. Many questions remain including the mode of transmission, the period of incubation and the true disease burden. Three forms of PNTM are described based on distinct pathology. The three forms comprise fibro-cavitary disease, nodular bronchiectasis disease, and hypersensitivity pneumonitis. Given the generally low virulence of these organisms together with their slow growth rate, onset of disease symptoms is often insidious. Incubation periods can vary from months to years making diagnosis difficult and tracing the source of infection virtually impossible. A rise in the number of globally documented NTM infections has led to NTM being recognized as emerging threat causing significant morbidity and mortality in both immune competent and immune compromised populations (12). MAC and MABS are the most common organism groups causing PNTM worldwide $(13,14)$.

\section{Risk Groups for NTM Disease}

NTMs are considered opportunistic pathogens to humans. Exposure to these organisms in day-to-day life is common through shower aerosols but infection and clinical disease occur in only some individuals (8). Over the last decades it has become apparent that several groups of individuals are prone to PNTM disease (Figure 1). These include patients with both genetic or acquired structural lung diseases such as cystic fibrosis (CF), chronic obstructive pulmonary disease (COPD), non-CF bronchiectasis, alpha-1 antitrypsin deficiency, previous pulmonary tuberculosis, and lung cancer (16-18). Patients with immune suppression due to primary immune deficiency syndromes (PIDs) such as Mendelian Susceptibility to Mycobacterial Disease (MSMD) associated with IL12-p40, IL12, IFN $\gamma$ receptor abnormalities and gene deformities (IFN $\gamma \mathrm{R} 1$, IFN $\gamma$ R2, IL12RB1, IL12B, STAT1, IKBKG, CYBB, ISG15, IRF8, GATA2) are at high risk of NTM infection (19-21). In addition, patients with acquired immunodeficiency syndromes including AIDS and hematological malignancies, hairy cell leukemia in particular, are also identified as susceptible to NTM infection (22). The latter groups of patients however, usually develop disseminated NTM infection (DNTM) rather than isolated pulmonary NTM infection (PNTM) which is seen in patients with structural lung disease and are considered a separate risk group (Figure 1). Other acquired states of immune deficiency, such as haematopoietic stem cell transplantation and solid organ transplantation are also predisposed to NTM infection. However, these patients could present with PNTM, DNTM, or other extra pulmonary sites of NTM infection (23). Other specific PIDs like Severe Combined Immune Deficiency (SCID) are commonly associated with BCGiosis, while Common Variable Immune Deficiency (CVID) predisposes patients to bronchiectasis which, in-turn, can lead to PTNM infection (21).

The increase in research into the epidemiology, diagnostics, and treatment of this once obscure disease stems from the increasing numbers of cases being identified from populations with previously unknown and currently unidentified risk factors (12). Advances in therapeutics in all fields of medicine have seen unexpected NTM disease susceptibilities emerge which pose a challenge in terms of patient care but also provide insight into disease pathology. For example, the susceptibility of patients with rheumatoid arthritis on anti-TNF therapy 


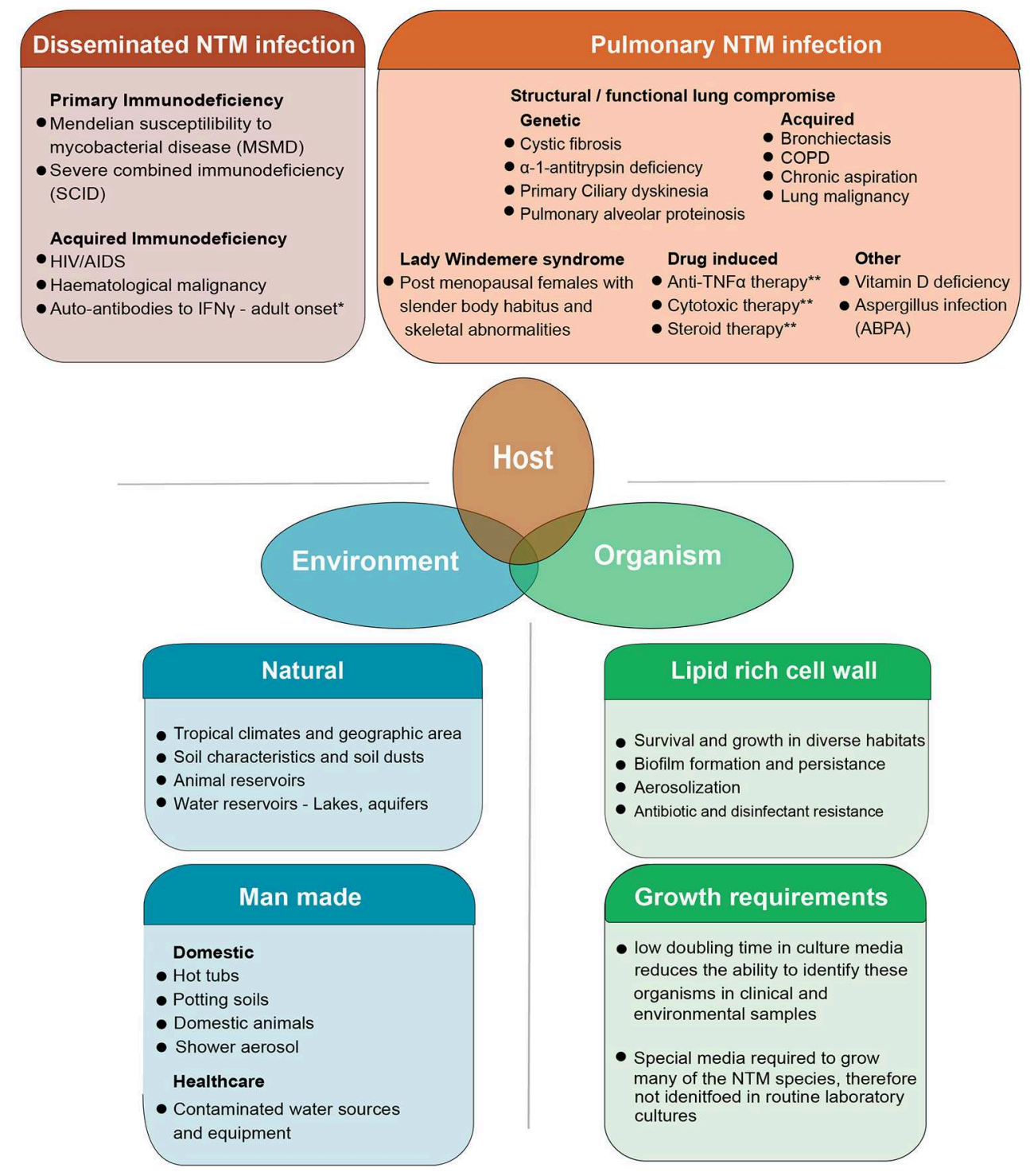

FIGURE 1 | The combined host, environmental and organism risk factors that contribute to developing NTM disease. NTM disease can manifest as pulmonary infection or the more severe disseminated form of the disease which is seen in patients with some severe systemic immune compromise. Pulmonary infection is seen in patients who have structural or functional lung defects that lead to innate immune compromise as well as other groups of patients in whom the precise nature of immune compromise is not clearly defined. Some degree of overlap exists in these risk groups with some patients with systemic immune compromise presenting with pulmonary disease well (15). Environmental risk factors include the natural and man-made habitats where these organisms survive and thrive. Increasing overlap between human habitation and NTM habitats is postulated as a reason for the increasing trend in infection. Organism biology also contributes to infection. NTM are a diverse group of organisms, tolerant to a wide range of physical conditions. Their lipid rich cell wall facilitates biofilm formation and aerosolization of bacteria while simultaneously mediated inherent resistance to many antibiotics and disinfectants. This makes both removing organisms from the man made habitats like water pipes as well as treating patients with active infection, difficult. The specific requirements needed to isolate these organisms in laboratory cultures has meant that NTM are often missed in routine sampling. Though not directly a risk factor for developing infection, this is one of the reasons infections are often missed at early stages. ${ }^{1}$ Autoantibodies to IFN $\gamma$ are commonly seen in in adults and have been extensively described in East Asian populations. A genetic component to auto antibody formation is likely with specific HLA types being associated with the disease. Both DNTM and PNTM disease manifestations are observed. ${ }^{2}$ Pulmonary alveolar proteinosis has a genetic-based form and acquired form. The genetic-based form is due to gene mutation in GM-SCF subunits and the acquired form is due to auto-antibodies against GM-CSF. This results in impaired surfactant disposal which accumulates in the lung and macrophages leading to dysfunction. ${ }^{3} \mathrm{Patients}$ on anti-TNF therapy and cytotoxic therapy are predisposed to both PNTM and DNTM though lung disease is more common. COPD, Chronic Obstructive Pulmonary disease; ABPA, Allergic Broncho Pulmonary Aspergillosis.

(infliximab, adalimumab, golimumab, and certolizumab) to NTM infections is a prime example of unexpected NTM susceptibility (24-26). These patients commonly present with
PNTM disease though extra pulmonary manifestations are also common. DNTM infections are rare though they have been described (27). 
A fourth disease cohort include elderly white postmenopausal females who present classically with NTM infection of the middle or lingular lobe of the lung. Described as "Lady Windermere syndrome" these patients often have a distinct physical phenotype of slender build, pectus excavatum or scoliosis and mitral valve prolapse, though notably they have no known immune dysfunction (16, 19, 28). Recently identified genetic defects that could contribute to susceptibility in these "Lady Windemere" patients include cystic fibrosis transmembrane conductance regulator gene (CFTR) related mutations, ciliary function, and other connective tissue related genetic defects as well as the DNA damage response protein TTK defects $(22,29-31)$. Finally, gastro-esophageal reflux disease (GORD), vitamin D deficiency, rheumatoid arthritis $(26,32,33)$ and low body mass index (BMI) are art risk of NTM lung disease (34). The acquire and genetic risk factors for NTM infection, both PNTM and DNTM are discussed in a recent reviews by Honda et al. (35) and Henkle et al. (23) showing the many forms and known susceptibilities the disease takes.

\section{The Global Disease Burden of NTM}

Studies from North America, Europe, and Asia have all shown increasing NTM disease incidence over the last two decades. Estimated NTM disease prevalence rose from 2.4 cases/100,000 in the early 1980 s to 15.2 cases/100,000 in 2013 in the US (36). The prevalence in the elderly population ( $>65$ years) more than doubled from 20 cases/100,000 to 47 cases /100,000 population between 1997 and 2007 (37). Multiple studies in five US states showed NTM positive culture rates increased from 8.2 cases/100,000 in 1994 to 16 cases/100,000 in 2014 (38). Similar figures are recorded in a Canadian study published in 2017 with disease prevalence increasing from 4.65 cases/100,000 in 1998 to 9.08 cases/100,000 in 2010. Laboratory isolation rate increased from 11.4 isolates/100,000 in 1998 to 22.22 isolates/100,000 in 2010 (39). The prevalence of NTM disease in non-cystic fibrosis (NCF) bronchiectasis in the US is estimated as $37 \%$ with the most common isolate being MAC (37). Laboratory isolation of NTM are now more common than $M$. tuberculosis in the US and Canada with an increase of $8.4 \%$ annually being documented between 1997 and 2003 (17). A study from the UK showed similar increases with the NTM infection rates more than tripling from 0.9 cases/100,000 in 1995 to 2.9 cases/100,000 in 2006 (40). Similar rates have been documented in Denmark (41) and Germany (42).

Studies in South Korea showed a 62\% increase in NTM lung disease from 2002 to 2008 with a marked increase in MABS infection (43). This is in contrast to European studies that show a predominance of MAC infection $(44,45)$ Numbers from Japan have shown a marked increase in both NTM infection and mortality from 1994 to 2010 (46) while a population-based Chinese study showed an increase in NTM isolation rate from 3 to $8.5 \%$ from 2008 to 2012 (47). As NTM disease is not a notifiable disease in most countries, accurate epidemiological data is limited, particularly in countries with low development indices. Nonetheless, an increasing number of NTM cases have been recorded in Brazil, Taiwan and the Middle East (48-52).
Globally, the most common NTM pathogens are the MAC organisms though prevalence varies greatly with geographic region, gender, and age (49). MABS are a significant problem particularly because of very high levels of antibiotic resistance and the disease a growing problem in East Asian countries including Japan, Korea, and Taiwan (53). NTM are also a particularly difficult problem in patients with cystic fibrosis, which is the most common genetics disease in Caucasians, whom are highly prone to MABS infection (40).

Cultures from CF patients have an $~ 10,000$-fold higher NTM prevalence compared with the general population (21). NTM isolation rates in $\mathrm{CF}$ vary from 3 to $17 \%$ with an increase in median prevalence from 9 to $13 \%$ seen in pre- and postmillennial studies (54). Increased prevalence of NTM positive cultures is seen with increasing age (55). Prevalence rates in the Australian adult CF population was $4.1 \%$ in a $2001-2014$ retrospective study carried out in Queensland (56). Though not as common as other bacterial pathogens, NTM infection was recognized as an important clinical entity in these patients as it was associated with significant deterioration in lung function (57). A geographical variance is seen in NTM species prevalent in the $\mathrm{CF}$ population, with MABS and MAC remaining the most common PNTM infections in these regions (54). Genetic mutations in CF patients are associated with PNTM (58).

NTM pathology has been a notifiable disease in Queensland (QLD), Australia since the commencement of the tuberculosis (TB) control programme in the 1960s and is currently a notifiable disease $(59,60)$. The increase in disease incidence in QLD over the last several decades has been clearly documented. Clinical cases of MAC disease were reported as 0.63 cases/100,000 in 1985, 1.21 cases/100,000 in 1994 and 2.2 cases/100,000 in 1999 (59). Significant NTM species isolation rates then rose from 9.1 cases/100,000 to 13.6 cases/100,000 from 1999 to 2005. In total, 1,171 isolates were reported in 2016 which is almost double the 672 isolates reported for the same period in 2012 (60). An increase in MABS isolates was also seen during this period. Of note, there was a change in the gender distribution from male predominance in 1999 to female predominance in 2005, particularly in the elderly population (59). Overall, a pattern of increasing non-cavitary disease in elderly females at a rate of 2.2-3.2 cases/100,000 population per year has emerged. Similarly, an increase in NTM disease has also been seen in the Northern Territory (NT), Australia from 1989 to 1997 (61). Regarding infection sources, subsequent investigation showed MAC, and MABS were present in household and municipal water sources and shower aerosols in homes (62-64). Projections show cases could more than triple between 2020 and 2040 [up to 6,446 cases a year (CI 15 just in QLD] (Figure 2).

\section{THE TREATMENT, COMPLICATIONS, AND ECONOMIC BURDEN OF NTM}

PNTM treatment requires prolonged (12-18 months) multi-drug therapy (66). Disease remission rates vary depending on infecting species, patient age and comorbidities $(37,67)$. Recurrence is common with rates of $30-50 \%$ being recorded in MAC infection 


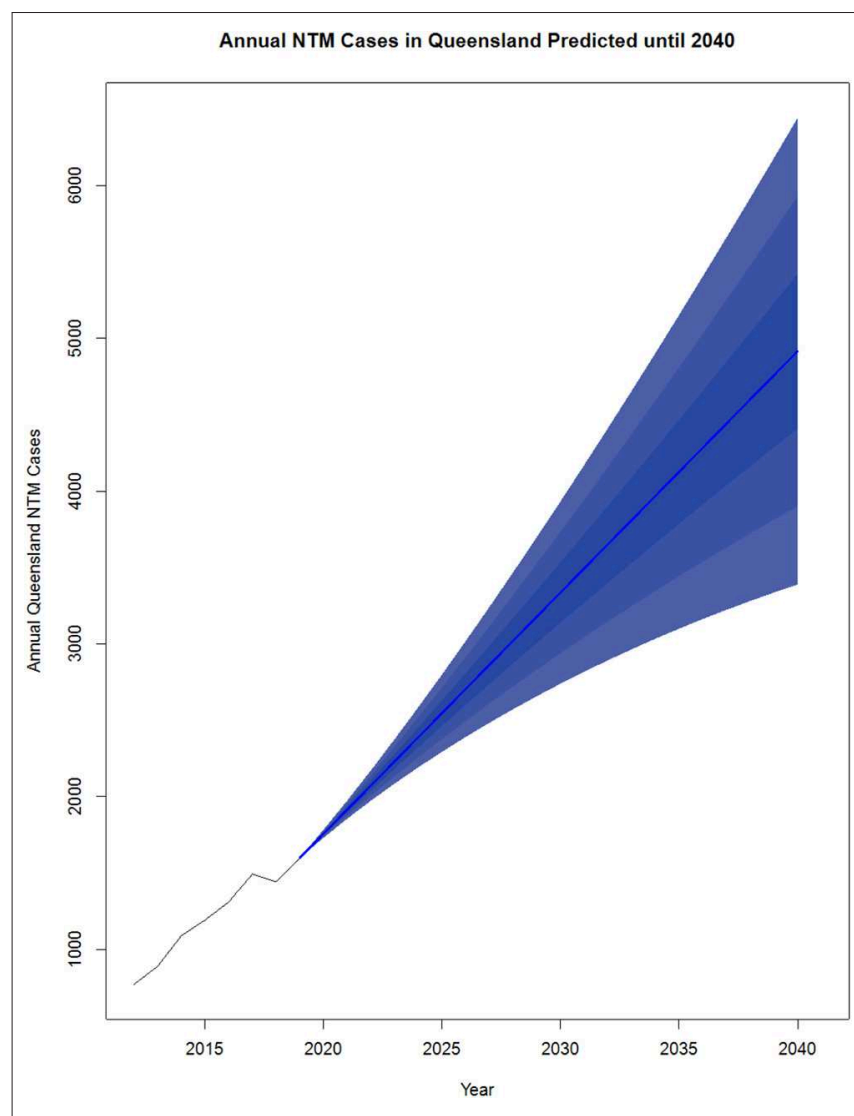

FIGURE 2 | Projected NTM cases in Queensland, Australia from 2020 to 2040. NTM cases from 2012 to 2019 were reported by the Epidemiology and Research Unit, QLD Department of Health and analyzed using R v3.5.2. The existing data was converted to a time series object using data from 2012 to 2019. The R package forecast (65) was used to generate the predictions from 2020 to 2040. The order for the model was estimated using the auto. arima() function which takes in a time series and returns the best AutoRegressive Integrated Moving Average (ARIMA) model according to either AIC, AICc, or $\mathrm{BIC}$ value. Each model was input to the forecast function with levels average, 5,10 , and 25 plotted.

(68). The majority of these recurrences are due to reinfection $(69,70)$ as opposed to relapse. MABS infection is more likely to result in treatment failure and recurrence. Many patients develop persistent chronic infection despite treatment while others succumb to the disease $(5,67)$. Side effects of antibiotics are numerous, and regimes are difficult to tolerate. Treatment is at high cost (USD \$14,730 for MAC infection and USD \$47,240 for MABS infection) (67). Of concern, long term treatment with multiple antibiotics increases antibiotic resistance and there is now evidence of person-to-person transmission of NTM (67). A multicentre study of MAC infection across Canada, France, Germany and the UK conducted in 2018 showed average direct medical costs per person year ranged from \$US12,200 in Canada to $\$ U S 25,500$ in France (71). In addition to direct disease related costs, patients were also shown to have six times higher secondary care utilization events for disease-related and disease-unrelated illnesses (18).
Adjuvant therapies have been tested with little success. Preliminary trials of adjunctive IFN $\gamma$ therapy were abandoned due to lack of response (72-74) although early case studies performed in patients with refractory disease showed promise $(75,76)$. IFN $\gamma$ therapy (by intramuscular injection, as opposed to the original trials done with nebulized IFN $\gamma$ ) showed promise in a recent study (77) but no other studies have supported these results (34). Other immune modulatory agents tested include recombinant IL-12 in mice $(78,79)$ and GM-CSF in HIV infected patients $(80,81)$. A phase 2 open labeled drug trial is currently underway to test the efficacy of inhaled GM-CSF in persistent NTM infection (NCT03421743).

\section{The Host-Bacterial Interaction}

NTM are not classic species-specific pathogens, rather they are environmental saprophytic organisms that make use of the new living opportunity presented when human habitation and bacterial habitation overlap. Unknowns include: (i) the percentage of a given population who are exposed; (ii) how infection occurs and by what source; (iii) what host and bacterial factors determine clearance; (iv) how NTM establishes itself as a colonizer without causing tissue invasion and; (v) why NTM are symptomatic in only some individuals. All that is currently known is that specific groups of individuals are at risk, some with known immune dysfunction, and others with specific medical characteristics.

\section{The Immune Response in Pulmonary NTM Infection}

The immune responses seen in human NTM infection has shown similarities to TB. However, no consistent phenotype of immune protection or immune susceptibility has been described. Immune compromise caused by genetic mutations (MSMD) and acquired defects due to infections like HIV usually lead to disseminated infection while iatrogenic causes (inhaled or systemic corticosteroids, anti-TNF therapy, chemotherapeutic agents), and defects in lung structural and functional integrity (primary ciliary dyskinesia and other mutations leading to ciliary dysfunction, CFTR mutations, bronchiectasis, COPD, $\alpha 1$ antitrypsin deficiency, lung malignancy, and ATT) and pulmonary alveolar proteinosis, are known predispositions to pulmonary NTM disease $(18,22,82)$. Previous or concomitant TB infection and Aspergillosis independently increase risk of PNTM (83).

These predispositions tell a story of both local/systemic and innate/adaptive immunity being required to combat infection. Innate defense mechanisms such as effective respiratory epithelial ciliary function are likely required to keep colonizing NTM bacterial counts under control. When airway mucociliary clearance is impaired and/or when virulent strains of bacteria can locally invade tissue, cellular defense mechanisms are activated. The immune cascade then follows: (i) macrophage activation and local recruitment of innate cells including neutrophils, iNKTs and NK cells to control early infection and; (ii) migration to of APCs to lymph nodes for antigen presentation and activation of antigen specific T cells. A review by Tomioka (84) describes the cytokines and other factors involved in macrophage activation as well as the key players involved in transforming naïve $\mathrm{T}$ cells 
to either Th1 type or Th2 type during mycobacterial infection. Macrophages and NK cells release IL-12/ IFN $\gamma$ to guide T cells toward a Th1 type phenotype. Th1 IFN $\gamma$ and IL-2 release then promote intracellular killing of mycobacteria. The exact triggers for a Th2 type response are not known, but should a Th2 type response predominate, Type 2 cytokines (IL-4, IL-10, and IL-13) promote suppressive pathways that increased Treg cell frequency.

Mouse studies have shown that ROR $\gamma \mathrm{t}$ induced Th17/IL17 responses during MAC infection promote pulmonary inflammation (85). However, the mechanism/s and correlates of protection of these responses during the various stages of this chronic disease are not understood. Other studies in the mouse models or murine cells models of NTM infection have shown the importance of CCL2, CCL5, and TLR signaling via MAPK, MyD88, and NFк $\beta$ for disease protection (86-88). Robust mouse models for $M$. avium infection exist though currently, it is difficult to initiate infection, maintain infection, and measure immune responses in MABS mouse models $(89,90)$. While comparisons between immune competent and immune deficient mouse models have provided insight into immune dysfunctions associated with DNTM (90), the chronic stages of PNTM infection, which are of current clinical relevance are not yet fully reproducible in mice.

Laboratory and clinical studies of mycobacteria immunity have shed light on some aspects of why opportunistic infections occur. Most studies have either measured cytokine levels directly in serum or cell culture supernatants where cell preparations have been stimulated with antigens or other non-specific mitogens such as lipopolysaccharide (LPS), which activates myeloid cells, or phytohaemaglutinin (PHA), which stimulates cellular immunity. A comparison of MAC infected patients with no evidence of compromised immunity and $M$. avium sensitin skin test positive healthy controls, showed that infected patient peripheral blood mononuclear cells (PBMCs) stimulated with mycobacterial antigens produced higher levels of IL-10 but lower levels of IFN $\gamma$, IL-12, and TNF. Other studies have shown similar results for IFN $\gamma$ and IL-10 but not for the other cytokines (9194). A study of serum cytokine levels comparing newly diagnosed MAC patients showed a significant reduction in IL-6, IL-8, IL23, IFN $\gamma$, and CD40L (95). Longitudinal assessment of Th1 and Th17 cytokines in these patients after 1 year of antibiotic therapy showed that while low Th1 cytokine levels could accelerate infection, Th17 cytokine levels at diagnosis (IL-17 and IL-23) could act as indicators of treatment outcome (sputum conversion vs. failure). A comparison of immune responses in MAC and MABS infection showed that MABS stimulated PBMC produced higher levels of TNF, IFN $\gamma$, IL- $1 \beta$, and MIP- $1 \alpha$ than MAC stimulated PBMC (96). A study that compared IFN $\gamma$, IL-12, and IL-10 production in response to mitogen-stimulated PBMCs in patients with MAC, MABS and healthy controls showed a reduction in IL-10 production in patients (97). A more comprehensive study, that used multiplexed bead-based assays to evaluate 22 cytokines in 24 MABS patients, showed reduced levels of IFN $\gamma$, IL-12, IL-4, and IL-13 and high levels of IL-17 and IL-23 in patients. A hi-dimensional flow analysis between individuals at risk and not at risk of MABS disease revealed immune exhaustion in T cells (CTLA-4) may be playing a role
(98). These finding is similar to studies performed in MAC infection $(93,95)$. Interestingly, levels of monokine induced by IFN $\gamma$ (MIG) and IFN $\gamma$ induced protein (IP-10) could predict treatment outcome (99). A recent small study on cytokine levels in three CF patients with MABS infection compared to three patients with non-CF PNTM infection and healthy controls showed no difference in TNF and IL-1 $\beta$ levels between CF and non-CF patients, however the non-CF patients showed higher TNF and IL- $1 \beta$ production following LPS stimulation (100). A hidimensional flow analysis between CF individual at risk and not at risk of MABS disease revealed a several immune biomarkers with a combined Akaike information criterion (AIC) of -30 and an area under the curve (AUC) of 1 (101). Additionally, the at risk CF patients showed a clear deficiency in $\mathrm{TNF} \alpha$ release from both $\mathrm{CD}^{+}{ }^{+}$and $\mathrm{CD}^{+}$subsets.

Preliminary evidence showed that $\mathrm{T}$ cell defects may play a role in MAC infection (102). T cells from healthy control subjects exhibited superior MAC growth inhibition in monocytes compared with patients. A recent study by Shu et al. (103) showed higher PD1 expression in T cell in patients with MAC lung disease compared to controls. This study also showed reduced IFN $\gamma$ and TNF production in MAC patients which was partially corrected after 2 months of antibiotic treatment and could also be further increased by blocking PD-1. However, this report did not study $\mathrm{T}$ cell function. A study using monocyte derived macrophages (MDM) showed no difference in MDM cytokine responses between patients and controls (104) while a more recent study showed that Keap 1 (an oxidative stress sensor) negatively regulated inflammatory signaling from primary macrophages in MAC infection (105). Other studies of TLR and dectin-based signaling in MAC and MABS infections showed TLR signaling to be crucial $(96,104-106)$. In addition, MAPK signaling, ERK1/2 and p38 have been shown to be down regulated in patients with MABS infection with subsequent reduction in TNF, IL6, and IL10 (107). Similar to studies in TB, different strains of NTM have been shown to elicit different immune responses in both human cells and murine models showing the importance of pathogen genetics on the host response $(101,108)$.

Studies on human cells have varied in the specimen used [PBMC, broncho-alveolar lavage (BAL) fluid and whole blood], the stimulants used (PHA, LPS, neutralized bacteria) and patient groups (age, infecting species, and stage of treatment) as shown in Table 1, making both cross-study comparisons and interpretation challenging. In addition, patient age ranges often vary widely, including multiple risk groups, and other confounders.

Indirect evidence suggests individuals prone to NTM infection have underlying immune dysfunction. Mutations known to cause susceptibility include those affecting IL12 $\beta$, IL12R $\beta 1$, IFN $\gamma$ R1, IFN $\gamma$ R2, and transcription factor STAT1 and RORC (109). Deficiency in NFK $\beta$ essential modulator (NEMO) and other primary immunodeficiency syndromes like GATA2 deficiency and isolated $\mathrm{CD}^{+}{ }^{+} \mathrm{T}$ cell deficiency have also been implicated in NTM susceptibility $(21,110)$. A recent study showed association between TNFA-1031 and IL10-1082 alleles and NTM infection (111). Additionally, HIV infection 
TABLE 1 | Summary of immune cytokine profiles during in vitro studies of patient immune responses in PNTM infection.

\begin{tabular}{|c|c|c|c|c|c|c|c|}
\hline Study population & Patient \# & Organism & Sample & Stimuli & Measurement & Result & References \\
\hline $\begin{array}{l}\text { PNTM patients before or during } \\
\text { treatment vs. MTB }{ }^{a} \text { patients vs. } \\
\mathrm{HC}^{b}\end{array}$ & 32 & $\begin{array}{l}\text { MAC and } \\
\text { M. kansasii }\end{array}$ & $\begin{array}{l}\text { PBMC } \\
\text { supernatant }\end{array}$ & $\begin{array}{l}\text { PHA }^{c} \text {, anti-CD3, } \\
\text { PPD }^{d} \text {, and viable } \\
\text { NTM }\end{array}$ & $\begin{array}{l}\text { Cytokines by } \\
\text { ELISA }\end{array}$ & Patients $-\downarrow$ IFN $\gamma$ and TNF & (92) \\
\hline $\begin{array}{l}\text { PTNM patients before or during } \\
\text { treatment vs. HC that were MAC } \\
\text { sensitin+ }\end{array}$ & 26 & MAC & $\begin{array}{l}\text { PBMC and BAL } \\
\text { supernatant }\end{array}$ & $\begin{array}{l}\text { Heat killed MAC and } \\
\text { MTB }\end{array}$ & $\begin{array}{l}\text { Cytokines by } \\
\text { ELISA and ICS }\end{array}$ & $\begin{array}{l}\text { Patients }-\uparrow \text { IL10 (produced } \\
\text { by T cells and monocytes) } \\
\text { and } \downarrow \text { IFN } \gamma, \text { IL12 and TNF }\end{array}$ & (90) \\
\hline PNTM patients vs. HC & 29 & $\begin{array}{l}\text { MAC and } \\
\text { MABS }\end{array}$ & $\begin{array}{l}\text { PBMC } \\
\text { supernatant }\end{array}$ & $\begin{array}{l}\text { PHA +/- IL12 and } \\
\text { LPS +/-IFN } \gamma\end{array}$ & $\begin{array}{l}\text { Cytokines by } \\
\text { ELISA }\end{array}$ & $\begin{array}{l}\text { Patients- } \downarrow \text { IFN } \gamma \text {, TNF, and } \\
\text { IL12p40 }\end{array}$ & (96) \\
\hline $\begin{array}{l}\text { PNTM patients before or during } \\
\text { treatment vs. HC (related) } \\
\text { or HC (general population) }\end{array}$ & 17 & MAC & $\begin{array}{l}\text { PBMC } \\
\text { supernatant }\end{array}$ & $\begin{array}{l}\text { SEB }^{g}, \mathrm{PPD} \text {, and } \\
\text { MAC sensitin }\end{array}$ & $\begin{array}{l}\text { Cytokines by } \\
\text { ELISA and ICS }\end{array}$ & $\begin{array}{l}\text { Patients }-\uparrow \text { IL } 10, \mathrm{IFN} \gamma \\
\mathrm{IFN} \gamma+\text { by CD4+ T cells and } \downarrow \\
\text { IL17 }\end{array}$ & (93) \\
\hline $\begin{array}{l}\text { PNTM patients before treatment } \\
\text { vs. HC }\end{array}$ & 42 & MAC & Serum & & Cytokine array & $\begin{array}{l}\text { Patients - } \downarrow \text { CD4OL, IFN } \gamma \text {, IL6, } \\
\text { IL8, and IL23 }\end{array}$ & (94) \\
\hline
\end{tabular}

aMTB: Mycobacterium tuberculosis.

${ }^{b} \mathrm{HC}$ : Healthy Controls.

cPHA: Phytohaemagglutinin.

${ }^{d} P P D$ : Purified Protein Derivative.

ePMA: Phorbol myristate acetate.

${ }^{f} B A L$ : Bronchoalveolar lavage fluid.

gSEB: Staphylococcal enterotoxin B.

hICS: Intracellular cytokine staining using flow cytometry.

iSame result for both MAC and MABS.

increases the risk of NTM disease when $\mathrm{CD}^{+} \mathrm{T}$ cell counts drops below $50 / \mathrm{mm}^{3}$. Broadly immunosuppressed patients with hematological malignancies, organ transplants, and stem cell transplants are at high risk. The timing of this increased risk does not coincide with the neutropenic phase of these diseases highlighting the lack of importance of neutrophil action in NTM immunity (21). Current available information supports the increased risk of NTM in patients being treated with antiTNF therapy (24). There is also evidence for increased risk in patients on the anti-IL6 agent tocilizumab while other agents including IL12/IL23 inhibitor ustekinumab (associated with TB reactivation), and the JAK pathway inhibitors tofacitinib and ruxolitinib (associated with IFN signaling interference) pose a theoretical risk. However, robust information is not yet available $(21,25)$.

NTM disease biomarkers (vs. airway colonization which is commonly seen in chronic lung diseases like CF, COPD, and bronchiectasis) are of high clinical value. Likewise, the identification of patients likely to recover and patients likely to develop serious life-threatening infection would be of enormous benefit to clinicians to guide the therapeutic decision-making process. Information from mouse models of MAC infection are available and less so for MABS. Human information is limited to small studies of generally $<10$ patients (89). Information is still lacking around the immune profiles of CF patients with MAC and MABS disease in comparison to non-CF patients with disease. Longitudinal follow-up information of the changes seen in the immune profile of these patients during treatment is also not available. In-depth analysis of the immune function and dysfunction seen in these groups of patients will provide much needed insight into disease pathophysiology and ultimately therapeutics (immune modulators etc) that could be developed and/or repurposed to enhance immune responses to these lifethreatening infections.

\section{RECENT DEVELOPMENTS AND RESEARCH PRIORITIES}

Recent findings of increased NTM pathophysiology are cause for global concern. Firstly, the recent emergence of person-toperson transmission of highly antibiotic resistant MABS across continents is highly alarming (11). These findings have led to new infection control practices in the US, UK, and Australia $(34,55,112)$. Secondly, evidence suggests there is increasing incidence of childhood NTM disease. A nationwide, populationbased study showed a significant increase in childhood NTM infection following a change in national policy on BCG vaccination from "universal" to "selective" (113). This study suggests that while BCG may provide some degree of protection to children from NTM infection, unvaccinated children, and other populations with respiratory deficits like CF could be a susceptible to this disease. Other studies have documented similar trends, particularly in relation to extra-pulmonary NTM infection in children, support this theory (114). Thirdly, it has been postulated that that MAC infection increases tumorgenes inflammatory responses which could lead to an increased risk of breast and lung cancer (115). Studies have associated 
NTM infection with diseases such as Sjogren's syndrome in Taiwan (116) and Sweets syndrome in Japan (117), though few, these studies highlight the possibility that NTM infection may catalyze non-infective sequalae that add to morbidity. Fourthly, there are alarmingly high death rates in patients following diagnosis with NTM lung infection. A systematic review showed a 5 years mortality showed $27 \%$ in Europe, $35 \%$ in the US and $33 \%$ in Asia (118). Predictors of high mortality included male gender, presence of comorbidities, and fibro cavitary disease. These findings have been validated in other studies that showed that male patients, with fibro cavitary disease, low BMI and malignancy were prognostic indicators of poor clinical outcome $(41,119,120)$. In addition, patients with persistent infection (those who remain culture positive despite 12 months of treatment) have higher rates of death attributable to NTM infection compared to those who manage to clear NTM in the sputum (34). Significantly higher numbers of hospitalizations due to illness, leading to increasing health care costs compound this issue (42).

Research priorities recommended in the US and UK include rapid diagnostic tools fast identification of infecting species (34) and simple and cheap screening tool to identify patients at risk $(83,98,112)$. These are considered high impact research goals that would alert clinicians to at risk patients enabling faster initiation of appropriate treatment and ultimately, superior care.

\section{DISCUSSION}

NTM infection presents a growing global health problem, complicated by ubiquitous exposure to the organisms, incomplete understanding of the immune susceptibility to disease, increasing numbers of immune compromised patients, cumbersome diagnostic tests (with no prognostic tests) and costly, multi drug treatment regimens that often fail to cure. However, we must keep in mind that different disease mechanisms may be operating between different risk groups and preclinical models.

NTM disease is frequently slow and progressive, affecting predominantly already vulnerable patient populations. Epidemiological and descriptive studies of patients are many, but gaps in knowledge remain. Foremost among these is a deconstruction of the immune susceptibilities to NTM lung disease. If we can understand potential patient risk profiles,

\section{REFERENCES}

1. Falkinham JO. Ecology of nontuberculous mycobacteria-where do human infections come from? Semin Respir Crit Care Med. (2013) 34:95-102. doi: 10.1055/s-0033-1333568

2. Johnson MM, Odell JA. Nontuberculous mycobacterial pulmonary infections. J Thorac Dis. (2014) 6:210-20. doi: 10.3978/j.issn. 2072-1439.2013.12.24

3. Hoefsloot W, van Ingen J, Andrejak C, Angeby K, Bauriaud R, Bemer P, et al. The geographic diversity of nontuberculous mycobacteria isolated from pulmonary samples: an ntm-net collaborative study. Eur Respir J. (2013) 421:604-13. doi: 10.1183/09031936.00149212 screening tests could be efficiently deployed to identify infection at risk individuals within hours. Such screening tests as well as prognostic tests that can predict outcome (disease remission vs. persistence, optimal treatment course, life changes etc) during early treatment would be extremely beneficial for clinicians to make therapy decisions as soon as possible, with potential improvement of patient outcomes. In the current age of immunotherapy, where targeted augmentation of immune responses is now possible, research into adjuvant immune therapies that could be used to "boost" a weakened immune system would beneficial and could be redeployed from the cancer field. Such immune modulating interventions would go a long way in reducing the global burden of NTM disease.

The true level of morbidity caused by NTM lung disease is slowly being revealed, in both developed and developing nations and in both immune competent and immune compromised populations. Disease burden is being documented in both childhood and adulthood disease in terms of both direct and indirect morbidity. A cohesive solution to the global challenge of NTM lung infection requires a multipronged approach involving not just epidemiological data, but also clinical and laboratorybased research for new diagnostics, prognostics, and treatments for use in machine learning. These cohesive approaches are urgent as NTM is more common in the warmer climates (60). Forty percent of the world's population live in the tropics ${ }^{1}$ and due to climate change, the tropic are expanding in area (121).

\section{AUTHOR CONTRIBUTIONS}

CR drafted the manuscript. VL, AK, DD, DR, MF, SB, RT, and JM provided critical revision.

\section{FUNDING}

JM was supported by a NHMRC CDF Level 2 Fellowship (1131732). DR and SB received support by Queensland Health Fellowships. This work was possible through a The University of Queensland Research Training Program (RTP), a James Cook International Research Training Program Scholarship (IRTPS) and a Rebecca L. Cooper Project Grant \#10509.

\footnotetext{
${ }^{1}$ Available online at: http://worldpopulationreview.com/countries/tropicalcountries/. (2019)
}

4. Gupta RS, Lo B, Son J. Phylogenomics and comparative genomic studies robustly support division of the genus mycobacterium into an emended genus mycobacterium and four novel genera. Front Microbiol. (2018) 9:67 doi: 10.3389/fmicb.2018. 00067

5. Nessar R, Cambau E, Reyrat JM, Murray A, Gicquel B. Mycobacterium abscessus: a new antibiotic nightmare. J Antimicrob Chemother. (2012) 67:810-8. doi: $10.1093 / \mathrm{jac} / \mathrm{dkr} 578$

6. Honda JR, Hasan NA, Davidson RM, Williams MD, Epperson LE, Reynolds PR, et al. Environmental nontuberculous mycobacteria in the hawaiian islands. PLoS Negl Trop Dis. (2016) 10:e0005068. doi: 10.1371/journal.pntd.0005068 
7. Honda JR, Virdi R, Chan ED. Global environmental nontuberculous mycobacteria and their contemporaneous man-made and natural niches. Front Microbiol. (2018) 9:2029. doi: 10.3389/fmicb.2018.02029

8. Nishiuchi $\mathrm{Y}$, Iwamoto $\mathrm{T}$, Maruyama F. Infection sources of a common non-tuberculous mycobacterial pathogen, Mycobacterium avium Complex. Front Med. (2017) 4:27. doi: 10.3389/fmed.2017. 00027

9. Morimoto K, Aono A, Murase Y, Sekizuka T, Kurashima A, Takaki A, et al. Prevention of aerosol isolation of nontuberculous mycobacterium from the patient's bathroom. ERJ Open Res. (2018) 4:00150-2017. doi: 10.1183/23120541.00150-2017

10. Gebert MJ, Delgado-Baquerizo M, Oliverio AM, Webster TM, Nichols LM, Honda JR, et al. Ecological analyses of mycobacteria in showerhead biofilms and their relevance to human health. MBio. (2018) 9:e01614-18. doi: 10.1128/mBio.01614-18

11. Bryant JM, Grogono DM, Rodriguez-Rincon D, Everall I, Brown KP, Moreno P, et al. Emergence and spread of a human-transmissible multidrugresistant nontuberculous mycobacterium. Science. (2018) 354:751-7. doi: $10.1126 /$ science.aaf8156

12. Griffith DE, Aksamit T, Brown-Elliott BA, Catanzaro A, Daley C, Gordin F, et al. An official ATS/IDSA statement: diagnosis, treatment, and prevention of nontuberculous mycobacterial diseases. Am J Respir Crit Care Med. (2007) 175:367-416. doi: 10.1164/rccm.200604-571ST

13. Tan Y, Su B, Shu W, Cai X, Kuang S, Kuang H, et al. Epidemiology of pulmonary disease due to nontuberculous mycobacteria in Southern China, 2013-2016. BMC Pulm Med. (2018) 18:168. doi: 10.1186/s12890-018-0728-z

14. Lim AYH, Chotirmall SH, Fok ETK, Verma A, De PP, Goh SK, et al. Profiling non-tuberculous mycobacteria in an Asian setting: characteristics and clinical outcomes of hospitalized patients in Singapore. BMC Pulm Med. (2018) 18:85. doi: 10.1186/s12890-018-0637-1

15. Un-In Wu, Holland SM. Host susceptibility to non-tuberculous mycobacterial infections. Lancet Infect Dis. (2015) 15:968-80. doi: 10.1016/S1473-3099(15)00089-4

16. Mirsaeidi M, Farshidpour M, Ebrahimi G, Aliberti S, Falkinham JO III. Management of nontuberculous mycobacterial infection in the elderly. Eur J Intern Med. (2014) 25:356-63. doi: 10.1016/j.ejim.2014.03.008

17. Taiwo B, Glassroth J. Nontuberculous mycobacterial lung diseases. Infect Dis Clin North Am. (2010) 24:769-89. doi: 10.1016/j.idc.2010.04.008

18. Axson EL, Bual N, Bloom CI, Quint JK. Risk factors and secondary care utilisation in a primary care population with non-tuberculous mycobacterial disease in the UK. Eur J Clin Microbiol Infect Dis. (2018) 38:117-24. doi: 10.1007/s10096-018-3402-8

19. Sexton P, Harrison AC. Susceptibility to nontuberculous mycobacterial lung disease. Eur Respir J. (2008) 31:1322-33. doi: 10.1183/09031936.00140007

20. Lee WI, Huang JL, Yeh KW, Jaing TH, Lin TY, Huang YC, et al. Immune defects in active mycobacterial diseases in patients with primary immunodeficiency diseases (PIDs). J Formos Med Assoc. (2011) 110:750-8. doi: 10.1016/j.jfma.2011.11.004

21. Lake MA, Ambrose LR, Lipman MC, Lowe DM. "Why me, why now?" using clinical immunology and epidemiology to explain who gets nontuberculous mycobacterial infection. BMC Med. (2016) 14:54. doi: 10.1186/s12916-016-0606-6

22. Baird TM, Thomson R. Diagnosis, classification and epidemiology of pulmonary non-tuberculous mycobacterial disease. In: Chalmers JD, Polverino E, Aliberti S, editors. Bronchiectasis (ERS Monograph). European Respiratory Society (2018).

23. Henkle E, Winthrop KL. Immune dysfunction and nontuberculous mycobacterial disease. In: Griffith DE editor. Nontuberculous Mycobacterial Disease, Respiratory Medicine, Switzerland, AG: Springer Nature (2019) 895-910. doi: 10.1007/978-3-319-93473-0_5

24. Wallis RS. Biologics and infections: lessons from tumor necrosis factor blocking agents. Infect Dis Clin North Am. (2011) 25:895-910. doi: 10.1016/j.idc.2011.08.002

25. Henkle E, Winthrop KL. Nontuberculous mycobacteria infections in immunosuppressed hosts. Clin Chest Med. (2015) 36:91-9. doi: 10.1016/j.ccm.2014.11.002

26. Liao TL, Lin CF, Chen YM, Liu HJ, Chen DY. Risk factors and outcomes of nontuberculous mycobacterial disease among rheumatoid arthritis patients: a case-control study in a TB endemic area. Sci Rep. (2016) 6:29443. doi: $10.1038 /$ srep29443

27. Winthrop KL, Chang E, Yamashita S, Iademarco MF, LoBue PA. Nontuberculous mycobacteria infections and anti-tumor necrosis factor-alpha therapy. Emerg Infect Dis. (2009) 15:1556-61. doi: 10.3201/eid1510.090310

28. Holt MR, Miles JJ, Inder WJ, Thomson RM. Exploring immunomodulation by endocrine changes in lady windermere syndrome. Clin Exp Immunol. (2019) 196:28-38. doi: 10.1111/cei.13265

29. Szymanski EP, Leung JM, Fowler CJ, Haney C, Hsu AP, Chen F, et al. Pulmonary nontuberculous mycobacterial infection. a multisystem, multigenic disease. Am J Respir Crit Care Med. (2015) 192:618-28. doi: 10.1164/rccm.201502-0387OC

30. McShane PJ, Glassroth J. Pulmonary disease due to nontuberculous mycobacteria: current state and new insights. Chest. (2015) 148:1517-27. doi: 10.1378/chest.15-0458

31. Chen F, Szymanski EP, Olivier KN, Liu X, Tettelin H, Holland $\mathrm{SM}$, et al. Whole-exome sequencing identifies the 6q12-q16 linkage region and a candidate gene, TTK, for pulmonary nontuberculous mycobacterial disease. Am J Respir Crit Care Med. (2017) 196:1599-604. doi: 10.1164/rccm.201612-2479OC

32. Yeh JJ, Wang YC, Sung FC, Kao CH. Rheumatoid arthritis increases the risk of nontuberculosis mycobacterial disease and active pulmonary tuberculosis. PLoS ONE. (2014) 9:e110922. doi: 10.1371/journal.pone.0110922

33. Winthrop KL, Iseman M. Bedfellows: mycobacteria and rheumatoid arthritis in the era of biologic therapy. Nat Rev Rheumatol. (2013) 9:524-31. doi: 10.1038 /nrrheum.2013.82

34. Haworth CS, Banks J, Capstick T, Fisher AJ, Gorsuch T, Laurenson IF, et al. British thoracic society guidelines for the management of non-tuberculous mycobacterial pulmonary disease (NTM-PD). Thorax. (2017) 72:ii1-64. doi: 10.1136/thoraxjnl-2017-210927

35. Honda JR, Alper S, Bai X, Chan ED. Acquired and genetic host susceptibility factors and microbial pathogenic factors that predispose to nontuberculous mycobacterial infections. Curr Opin Immunol. (2018) 54:6673. doi: 10.1016/j.coi.2018.06.001

36. Donohue MJ, Wymer L. Increasing prevalence rate of nontuberculous mycobacteria infections in five states, 2008-2013. Ann Am Thorac Soc. (2016) 13:2143-50. doi: 10.1513/AnnalsATS.201605-353OC

37. Mirsaeidi M, Farshidpour M, Allen MB, Ebrahimi G, Falkinham JO. Highlight on advances in nontuberculous mycobacterial disease in North America. Biomed Res Int. (2014) 2014:919474. doi: 10.1155/2014/ 919474

38. Donohue MJ. Increasing nontuberculous mycobacteria reporting rates and species diversity identified in clinical laboratory reports. BMC Infect Dis. (2018) 18:163. doi: 10.1186/s12879-018-3043-7

39. Brode SK, Marchand-Austin A, Jamieson FB, Marras TK. Pulmonary versus nonpulmonary nontuberculous mycobacteria, Ontario, Canada. Emerg Infect Dis. (2017) 23:1898-901. doi: 10.3201/eid2311.170959

40. Moore JE, Kruijshaar ME, Ormerod LP, Drobniewski F, Abubakar I. Increasing reports of non-tuberculous mycobacteria in England, Wales and Northern Ireland, 1995-2006. BMC Public Health. (2010) 10:612. doi: 10.1186/1471-2458-10-612

41. Andrejak C, Thomsen VO, Johansen IS, Riis A, Benfield TL, Duhaut P, et al. Nontuberculous pulmonary mycobacteriosis in Denmark: incidence and prognostic factors. Am J Respir Crit Care Med. (2010) 181:514-21. doi: 10.1164/rccm.200905-0778OC

42. Diel R, Jacob J, Lampenius N, Loebinger M, Nienhaus A, Rabe KF, et al. Burden of non-tuberculous mycobacterial pulmonary disease in Germany. Eur Respir J. (2017) 49:1602109. doi: 10.1183/13993003.02109-2016

43. Park Y, Lee C-H, Lee S-M, Yang S-C, Yoo C-G, Kim Y, et al. Rapid increase of non-tuberculous mycobacterial lung diseases in a tertiary refferal hospital in South Korea. Int J Tuberc Lung Dis. (2010) 14:1069-71.

44. van Ingen J, Bendien SA, de Lange WC, Hoefsloot W, Dekhuijzen PN, Boeree $\mathrm{MJ}$, et al. Clinical relevance of non-tuberculous mycobacteria isolated in the Nijmegen-Arnhem region, the Netherlands. Thorax. (2009) 64:502-6. doi: 10.1136/thx.2008.110957

45. Roux AL, Catherinot E, Ripoll F, Soismier N, Macheras E, Ravilly S, et al. Multicenter study of prevalence of nontuberculous mycobacteria in 
patients with cystic fibrosis in France. J Clin Microbiol. (2009) 47:4124-8. doi: 10.1128/JCM.01257-09

46. Morimoto K, Iwai K, Uchimura K, Okumura M, Yoshiyama T, Yoshimori $\mathrm{K}$, et al. A steady increase in nontuberculous mycobacteriosis mortality and estimated prevalence in Japan. Ann Am Thorac Soc. (2014) 11:1-8. doi: 10.1513/AnnalsATS.201303-067OC

47. Wu J, Zhang Y, Li J, Lin S, Wang L, Jiang Y, et al. Increase in nontuberculous mycobacteria isolated in Shanghai, China: results from a population-based study. PLoS ONE. (2014) 9:e109736. doi: 10.1371/journal.pone.0109736

48. Lai CC, Tan CK, Chou CH, Hsu HL, Liao CH, Huang YT, et al. Increasing incidence of nontuberculous mycobacteria, Taiwan, 2000-2008. Emerg Infect Dis. (2010) 16:294-6. doi: 10.3201/eid1602.090675

49. Prevots DR, Marras TK. Epidemiology of human pulmonary infection with nontuberculous mycobacteria: a review. Clin Chest Med. (2015) 36:13-34. doi: 10.1016/j.ccm.2014.10.002

50. Lima CA, Campos CE, Oelemann MA, Oliveira Mdo, Gomes HM, Ramos JP, et al. Nontuberculous mycobacteria in respiratory samples from patients with pulmonary tuberculosis in the state of Rondônia, Brazil. Mem Inst Oswaldo Cruz. (2013) 108:457-62. doi: 10.1590/S0074-0276108042013010

51. Sara H. Al-Mahruqi, Jakko van Ingen, Suleiman Al-Busaidy, Martin J. Boeree, Samiya Al-Zadjali, Arti Patel, et al. Clinical relevance of nontuberculous mycobacteria, Oman. Emerg Infect Dis. (2009) 15:292-4. doi: 10.3201/eid1502.080977

52. Fusco da Costa AR, Falkinham JO III, Lopes ML, Barretto AR, Felicio JS, Sales LH, et al. Occurrence of nontuberculous mycobacterial pulmonary infection in an endemic area of tuberculosis. PLoS Negl Trop Dis. (2013) 7:e2340. doi: 10.1371/journal.pntd.0002340

53. Sami Simons, Jakko van Ingen, Po-Ren Hsueh, Nguyen Van Hung, P.N. Richard Dekhuijzen, Martin J. Boeree, et al. Nontuberculous mycobacteria in respiratory tract infections, eastern asia. Emerg Infect Dis. (2011) 17:343-9. doi: 10.3201/eid170310060

54. Qvist T, Pressler T, Høiby N, Katzenstein TL. Shifting paradigms of nontuberculous mycobacteria in cystic fibrosis. Respir Res. (2014) 15:41. doi: 10.1186/1465-9921-15-41

55. Floto RA, Olivier KN, Saiman L, Daley CL, Herrmann JL, Nick JA, et al. US cystic fibrosis foundation and european cystic fibrosis society consensus recommendations for the management of non-tuberculous mycobacteria in individuals with cystic fibrosis. Thorax. (2016) 71(Suppl. 1):i1-22. doi: 10.1136/thoraxjnl-2015-207360

56. Ramsay KA, Sandhu H, Geake JB, Ballard E, O’Rourke P, Wainwright $\mathrm{CE}$, et al. The changing prevalence of pulmonary infection in adults with cystic fibrosis: a longitudinal analysis. J Cyst Fibros. (2017) 16:70-7. doi: 10.1016/j.jcf.2016.07.010

57. Esther CR Jr., Esserman DA, Gilligan P, Kerr A, Noone PG. Chronic Mycobacterium abscessus infection and lung function decline in cystic fibrosis. J Cyst Fibros. (2010) 9:117-23. doi: 10.1016/j.jcf.2009.12.001

58. Ziedalski TM, Kao PN, Henig NR, Jacobs SS, Ruoss SJ. Prospective analysis of cystic fibrosis transmembrane regulator mutations in adults with bronchiectasis or pulmonary nontuberculous mycobacterial infection. Chest. (2006) 130:995-1002. doi: 10.1378/chest.130.4.995

59. Thomson RM. Changing epidemiology of pulmonary nontuberculous mycobacteria infections. Emerg Infect Dis. (2010) 16:1576-83. doi: 10.3201/eid1610.091201

60. Thomson R, Donnan E, Konstantinos A. Notification of nontuberculous mycobacteria: an australian perspective. Ann Am Thorac Soc. (2017) 14:31823. doi: 10.1513/AnnalsATS.201612-994OI

61. O'Brien DP, Krause VL, Currie BJ. Nontuberculous mycobacterial disease in northern australia: a case series and review of the literature. Clin Infect Dis. (2000) 31:958-68. doi: 10.1086/318136

62. Thomson RM, Carter R, Tolson C, Coulter C, Huygens F, Hargreaves M. Factors associated with the isolation of Nontuberculous mycobacteria (NTM) from a large municipal water system in Brisbane, Australia. BMC Microbiology. (2013) 13:89. doi: 10.1186/1471-2180-13-89

63. Thomson R, Tolson C, Sidjabat H, Huygens F, Hargreaves M. Mycobacterium abscessus isolated from municipal water - a potential source of human infection. BMC Infect Dis. (2013) 13:241. doi: 10.1186/1471-2334-13-241

64. Thomson R, Tolson C, Carter R, Coulter C, Huygens F, Hargreaves M. Isolation of nontuberculous mycobacteria (NTM) from household water and shower aerosols in patients with pulmonary disease caused by NTM. J Clin Microbiol. (2013) 51:3006-11. doi: 10.1128/JCM.00899-13

65. Hyndman RJ, Khandakar Y. Automatic time series forecasting: the forecast package for R. J Stat Softw. (2008) 26:1-22. doi: 10.18637/jss.v027.i03

66. Philley JV, Griffith DE. Treatment of slowly growing mycobacteria. Clin Chest Med. (2015) 36:79-90. doi: 10.1016/j.ccm.2014.10.005

67. Kasperbauer SH, De Groote MA. The treatment of rapidly growing mycobacterial infections. Clin Chest Med. (2015) 36:67-78. doi: 10.1016/j.ccm.2014.10.004

68. Stout JE, Koh WJ, Yew WW. Update on pulmonary disease due to non-tuberculous mycobacteria. Int J Infect Dis. (2016) 45:123-34. doi: 10.1016/j.ijid.2016.03.006

69. Wallace RJ Jr., Brown-Elliott BA, McNulty S, Philley JV, Killingley J, Wilson RW, et al. Macrolide/Azalide therapy for nodular/bronchiectatic mycobacterium avium complex lung disease. Chest. (2014) 146:276-82. doi: 10.1378/chest.13-2538

70. Lee BY, Kim S, Hong Y, Lee SD, Kim WS, Kim DS, et al. Risk factors for recurrence after successful treatment of Mycobacterium avium complex lung disease. Antimicrob Agents Chemother. (2015) 59:2972-7. doi: 10.1128/AAC.04577-14

71. Goring SM, Wilson JB, Risebrough NR, Gallagher J, Carroll S, Heap $\mathrm{KJ}$, et al. The cost of Mycobacterium avium complex lung disease in Canada, France, Germany, and the United Kingdom: a nationally representative observational study. BMC Health Serv Res. (2018) 18:700. doi: 10.1186/s12913-018-3489-8

72. Thomson RM, Yew WW. When and how to treat pulmonary nontuberculous mycobacterial diseases. Respirology. (2009) 14:12-26. doi: 10.1111/j.1440-1843.2008.01408.x

73. Holland SM. Immunotherapy of mycobacterial infections. Semin Respir Infect. (2001) 16:47-59. doi: 10.1053/srin.2001.22728

74. Riddell LA, Pinching AJ, Hill S, Ng TT, Arbe E, Lapham GP, et al. A phase III study of recombinant human interferon gamma to prevent opportunistic infections in advanced HIV disease. AIDS Res Hum Retroviruses. (2001) 17:789-97. doi: 10.1089/088922201750251981

75. Holland SM, Eisenstein EM, Kuhns DB, Turner ML, Fleisher TA, Strober W, et al. Treatment of refractory disseminated nontuberculous mycobacterial infection with interferon gamma. A preliminary report. N Engl J Med. (1994) 330:1348-55. doi: 10.1056/NEJM199405123301904

76. Chatte G, Panteix G, Perrin-Fayolle M, Pacheco Y. Aerosolized interferon gamma for Mycobacterium avium-complex lung disease. Am J Respir Crit Care Med. (1995) 152:1094-6. doi: 10.1164/ajrccm.152.3.76 63788

77. Milanes-Virelles MT, Garcia-Garcia I, Santos-Herrera Y, Valdes-Quintana M, Valenzuela-Silva CM, Jimenez-Madrigal G, et al. Adjuvant interferon gamma in patients with pulmonary atypical Mycobacteriosis: a randomized, double-blind, placebo-controlled study. BMC Infect Dis. (2008) 8:17. doi: 10.1186/1471-2334-8-17

78. Kobayashi K, Kasama T, Yamazaki J, Hosaka M, Katsura T, Mochizuki $\mathrm{T}$, et al. Protection of mice from Mycobacterium avium infection by recombinant interleukin-12. Antimicrob Agents Chemother. (1995) 39:136971. doi: 10.1128/AAC.39.6.1369

79. Silva RA, Pais TF, Appelberg R. Evaluation of IL-12 in immunotherapy and vaccine design in experimental Mycobacterium avium infections. J Immunol. (1998) 161:5578-85.

80. Kemper CA, Bermudez LE, Deresinski SC. Immunomodulatory treatment of Mycobacterium avium complex bacteremia in patients with AIDS by use of recombinant granulocyte-macrophage colonystimulating factor. J Inf Dis. (1998) 177:914-20. doi: 10.1086/515249

81. Scott JP, Ji Y, Kannan M, Wylam ME. Inhaled granulocyte-macrophage colony-stimulating factor for Mycobacterium abscessus in cystic fibrosis. Eur Respir J. (2018) 51. doi: 10.1183/13993003.02127-2017

82. Renna M, Schaffner C, Brown K, Shang S, Tamayo MH, Krisztina Hegyi, et al. Azithromycin blocks autophagy and may predispose cystic fibrosis patients to mycobacterial infection. J Clin Invest. (2011) 121:3554-63. doi: 10.1172/JCI46095

83. Chalmers JD, Aksamit T, Carvalho ACC, Rendon A, Franco I. Nontuberculous mycobacterial pulmonary infections. Pulmonology. (2018) 24:120-31. doi: 10.1016/j.pulmoe.2017.12.005 
84. Tomioka H. Adjunctive immunotherapy of mycobacterial infections. Curr Pharmaceut Des. (2004) 10:3297-312. doi: 10.2174/1381612043 383232

85. Matsuyama M, Ishii Y, Sakurai H, Ano S, Morishima Y, Yoh K, et al. Overexpression of RORyt enhances pulmonary inflammation after infection with Mycobacterium avium. PLoS ONE. (2016) 11:e0147064. doi: 10.1371/journal.pone.0147064

86. Klug K, Ehlers S, Uhlig S, Reiling N. Mitogen-activated protein kinases p38 and ERK1/2 regulated control of Mycobacterium avium replication in primary murine macrophages is independent of tumor necrosis factor-alpha and interleukin-10. Innate Immun. (2011) 17:470-85. doi: $10.1177 / 1753425910377799$

87. Kim YS, Kim JH, Woo M, Kim TS, Sohn KM, Lee YH, et al. Innate signaling mechanisms controlling Mycobacterium chelonae-mediated CCL2 and CCL5 expression in macrophages. J Microbiol. (2015) 53:864-74. doi: 10.1007/s12275-015-5348-1

88. Feng CG, Scanga CA, Collazo-Custodio CM, Cheever AW, Hieny S, Caspar $\mathrm{P}$, et al. Mice lacking myeloid differentiation factor 88 display profound defects in host resistance and immune responses to Mycobacterium avium infection not exhibited by toll-like receptor 2 (TLR2)- and TLR4-Deficient animals. J Immun. (2003) 171:4758-64. doi: 10.4049/jimmunol.171.9.4758

89. Orme IM, Ordway DJ. Host response to nontuberculous mycobacterial infections of current clinical importance. Infect Immun. (2014) 82:3516-22. doi: 10.1128/IAI.01606-13

90. Baldwin SL, Larsen SE, Ordway D, Cassell G, Coler RN. The complexities and challenges of preventing and treating nontuberculous mycobacterial diseases. PLoS Negl Trop Dis. (2019) 13:e0007083. doi: 10.1371/journal.pntd.0007083

91. Vankayalapati R, Wizel B, Samten B, Griffith DE, Shams H, Galland $\mathrm{MR}$, et al. Cytokine profiles in immunocompetent persons infected with Mycobacterium avium complex. J Infect Dis. (2001) 183:478-84. doi: $10.1086 / 318087$

92. Safdar A, White DA, Stover D, Armstrong D, Murray HW. Profound interferon gamma deficiency in patients with chronic pulmonary nontuberculous mycobacteriosis. Am J Med. (2002) 113:756-9. doi: 10.1016/S0002-9343(02)01313-X

93. Greinert U, Schlaak M, Rusch-Gerdes S, Flad HD, Ernst M. Low in vitro production of interferon-gamma and tumor necrosis factoralpha in HIV-seronegative patients with pulmonary disease caused by nontuberculous mycobacteria. J Clin Immunol. (2000) 20:445-52. doi: 10.1023/a:1026407815946

94. Lim A, Allison C, Price P, Waterer G. Susceptibility to pulmonary disease due to Mycobacterium avium-intracellulare complex may reflect low IL-17 and high IL-10 responses rather than Th1 deficiency. Clin Immunol. (2010) 137:296-302. doi: 10.1016/j.clim.2010.07.011

95. Kim SY, Koh WJ, Park HY, Jeon K, Kwon OJ, Cho SN, et al. Changes in serum immunomolecules during antibiotic therapy for Mycobacterium avium complex lung disease. Clin Exp Immunol. (2014) 176:93-101. doi: $10.1111 /$ cei. 12253

96. Sampaio EP, Elloumi HZ, Zelazny A, Ding L, Paulson ML, Sher A, et al. Mycobacterium abscessus and M. avium trigger Toll-like receptor 2 and distinct cytokine response in human cells. Am J Respir Cell Mol Biol. (2008) 39:431-9. doi: 10.1165/rcmb.2007-0413OC

97. Kwon YS, Kim EJ, Lee SH, Suh GY, Chung MP, Kim H, et al. Decreased cytokine production in patients with nontuberculous mycobacterial lung disease. Lung. (2007) 185:337-41. doi: 10.1007/s00408-007-9040-z

98. Lutzky VP, Ratnatunga CN, Smith DJ, Kupz A, Doolan DL, Reid DW, et al. Anomalies in T Cell function are associated with individuals at risk of mycobacterium abscessus complex infection. Front Immunol. (2018) 9:1319. doi: 10.3389/fimmu.2018.01319

99. Kim SY, Koh WJ, Kim YH, Jeong BH, Park HY, Jeon K, et al. Importance of reciprocal balance of $\mathrm{T}$ cell immunity in Mycobacterium abscessus complex lung disease. PLoS ONE. (2014) 9:e109941. doi: 10.1371/journal.pone.0109941

100. Becker KL, van Ingen J, Ten Oever J, Merkus PJ, Ferwerda G, Netea MG, et al. Deficient interleukin-17 production in response to Mycobacterium abscessus in cystic fibrosis. Eur Respir J. (2016) 47:990-3. doi: $10.1183 / 13993003.00446-2015$
101. Aulicino A, Dinan AM, Miranda-CasoLuengo AA, Browne JA, Rue-Albrecht $\mathrm{K}$, MacHugh DE, et al. High-throughput transcriptomics reveals common and strain-specific responses of human macrophages to infection with Mycobacterium abscessus Smooth and Rough variants. BMC Genomics. (2015) 16:1046. doi: 10.1186/s12864-015-2246-1

102. Tsukaguchi K, Yoneda T, Okamura H, Tamaki S, Takenaka H, Okamoto Y, et al. Defective T cell function for inhibition of growth of Mycobacterium avium-intracellulare complex (MAC) in patients with MAC disease: restoration by cytokines. J Infect Dis. (2000) 182:1664-71. doi: $10.1086 / 317601$

103. Shu CC, Wang JY, Wu MF, Wu CT, Lai HC, Lee LN, et al. Attenuation of lymphocyte immune responses during Mycobacterium avium complexinduced lung disease due to increasing expression of programmed death-1 on lymphocytes. Sci Rep. (2017) 7:42004. doi: 10.1038/srep42004

104. de Jong E, Lim A, Waterer G, Price P. Monocyte-derived macrophages do not explain susceptibility to pulmonary non-tuberculous mycobacterial disease. Clin Transl Immunology. (2012) 1:e2. doi: 10.1038/cti.2012.1

105. Awuh JA, Haug M, Mildenberger J, Marstad A, Do CP, Louet C, et al. Keap1 regulates inflammatory signaling in Mycobacterium avium-infected human macrophages. Proc Natl Acad Sci USA. (2015) 112:E4272-80. doi: 10.1073/pnas.1423449112

106. Lee SJ, Shin SJ, Lee SJ, Lee MH, Kang TH, Noh KT, et al. Mycobacterium abscessus MAB2560 induces maturation of dendritic cells via Toll-like receptor 4 and drives Th1 immune response. BMB Rep. (2014) 47:512-7. doi: 10.5483/BMBRep.2014.47.9.001

107. Sim YS, Kim SY, Kim EJ, Shin SJ, Koh WJ. Impaired expression of MAPK is associated with the downregulation of TNF- $\alpha$, IL-6, and IL-10 in Mycobacterium abscessus lung disease. Tuberc Respir Dis. (2012) 72:275-83. doi: 10.4046/trd.2012.72.3.275

108. Bernadette M Saunders, Alison Dane, Briscoe H, Britton WJ. Characterization of immune responses during infection with Mycobacterium avium strains 100, 101 and the recently sequenced 104. Immunol Cell Biol. (2002) 80:544-9. doi: 10.1046/j.1440-1711.2002.01121.x

109. Haverkamp MH, van Dissel JT, Holland SM. Human host genetic factors in nontuberculous mycobacterial infection: lessons from single gene disorders affecting innate and adaptive immunity and lessons from molecular defects in interferon-gamma-dependent signaling. Microbes Infect. (2006) 8:115766. doi: 10.1016/j.micinf.2005.10.029

110. Sampaio EP, Bax HI, Hsu AP, Kristosturyan E, Pechacek J, Chandrasekaran $\mathrm{P}$, et al. A novel STAT1 mutation associated with disseminated mycobacterial disease. J Clin Immunol. (2012) 32:681-9. doi: 10.1007/s10875-012-9659-2

111. Affandi JS, Hendry S, Waterer G, Thomson R, Wallace H, Burrows S, et al. Searching for an immunogenetic factor that will illuminate susceptibility to non-tuberculous mycobacterial disease. Hum Immunol. (2013) 74:1382-5. doi: 10.1016/j.humimm.2013.06.019

112. Henkle E, Aksamit T, Barker A, Daley CL, Griffith D, Leitman P, et al. Patientcentered research priorities for pulmonary nontuberculous mycobacteria (NTM) infection. An NTM research consortium workshop report. Ann Am Thorac Soc. (2016) 13:S379-84. doi: 10.1513/AnnalsATS.201605-387WS

113. Kontturi A, Soini H, Ollgren J, Salo E. Increase in childhood nontuberculous mycobacterial infections after BCG coverage drop - a nationwide population-based retrospective study, Finland, 1995 to 2016. Clin Infect Dis. (2018) 67:1256-61. doi: 10.1093/cid/ciy241

114. SAGE Working Group on BCG Vaccinesand WHO Secretariat. Report on BCG Vaccine Use for Protection Against Mycobacterial Infections Including Tuberculosis, Leprosy, and Other Nontuberculous Mycobacteria (NTM) Infections. WHO (2017).

115. Philley JV, Hertweck KL, Kannan A, Brown-Elliott BA, Wallace RJ Jr, Kurdowska A, et al. 2018. Sputum detection of predisposing genetic mutations in women with pulmonary nontuberculous mycobacterial disease. Sci Rep. (2018) 8:11336. doi: 10.1038/s41598-018-29471-x

116. Chao WC, Lin CH, Liao TL, Chen YM, Chen DY, Chen HH. Association between a history of mycobacterial infection and the risk of newly diagnosed Sjogren's syndrome: A nationwide, population-based casecontrol study. PLoS ONE. (2017) 12:e0176549. doi: 10.1371/journal.pone.0 176549

117. Hibiya K, Miyagi K, Tamayose M, Nabeya D, Kinjo T, Takeshima S, et al. Do infections with disseminated Mycobacterium avium complex precede sweet's 
syndrome? a case report and literature review. Int J Mycobacteriol. (2017) 6:336-43. doi: 10.4103/ijmy.ijmy_172_17

118. Diel R, Lipman M, Hoefsloot W. High mortality in patients with Mycobacterium avium complex lung disease: a systematic review. BMC Infect Dis. (2018) 18:206. doi: 10.1186/s12879-018-3113-x

119. Kumagai S, Ito A, Hashimoto T, Marumo S, Tokumasu H, Kotani A, et al. Development and validation of a prognostic scoring model for Mycobacterium avium complex lung disease: an observational cohort study. BMC Infect Dis. (2017) 17:436. doi: 10.1186/s12879-0172544-0

120. Hayashi M, Takayanagi N, Kanauchi T, Miyahara Y, Yanagisawa T, Sugita Y. Prognostic factors of 634 HIV-negative patients with Mycobacterium avium complex lung disease. Am J Respir Crit Care Med. (2012) 185:575-83. doi: $10.1164 / \mathrm{rccm} .201107-1203 \mathrm{OC}$
121. Heffernan O. The mystery of the expanding tropics. Nature. (2016) 530:20-2. doi: $10.1038 / 530020 \mathrm{a}$

Conflict of Interest: The authors declare that the research was conducted in the absence of any commercial or financial relationships that could be construed as a potential conflict of interest.

Copyright (c) 2020 Ratnatunga, Lutzky, Kupz, Doolan, Reid, Field, Bell, Thomson and Miles. This is an open-access article distributed under the terms of the Creative Commons Attribution License (CC BY). The use, distribution or reproduction in other forums is permitted, provided the original author(s) and the copyright owner(s) are credited and that the original publication in this journal is cited, in accordance with accepted academic practice. No use, distribution or reproduction is permitted which does not comply with these terms. 